\title{
GlycoPEGylated recombinant factor IX for hemophilia $B$ in context
}

This article was published in the following Dove Press journal:

Drug Design, Development and Therapy

\section{Elena Santagostino Maria Elisa Mancuso}

Angelo Bianchi Bonomi Hemophilia and Thrombosis Center, IRCCS Ca' Granda Foundation, Maggiore Hospital Policlinic, Milan, Italy
Correspondence: Elena Santagostino Angelo Bianchi Bonomi Hemophilia and Thrombosis Center, IRCCS Ca' Granda Foundation, Maggiore Hospital Policlinic, Via Pace 9, Milan 20122, Italy

Tel +390255035273

Fax +39025503 4439

Email elena.santagostino@policlinico.mi.it
Abstract: Decisions over hemophilia treatment selection and switching involve balancing many clinical and patient-related factors. The current standard of care for patients with hemophilia B is prophylaxis with plasma-derived or recombinant factor IX ( $\mathrm{rFIX}$ ) concentrates. However, several extended half-life (EHL) rFIX products have recently been developed to improve treatment convenience and clinical outcomes for these patients. Nonacog beta pegol, an rFIX product that combines the FIX protein with a $40 \mathrm{kDa}$ polyethylene glycol moiety, has been evaluated in 115 previously treated patients with hemophilia B (including 25 children) in the paradigm clinical trial program. FIX activity levels and pharmacokinetics were monitored throughout these trials and showed that nonacog beta pegol offers significant pharmacological improvements over standard FIX products. Once-weekly prophylaxis with nonacog beta pegol $40 \mathrm{IU} / \mathrm{kg}$ resulted in fewer bleeds in all patients (median annualized bleeding rate of 1.0 across all ages), resolved $90 \%$ of target joints, and improved health-related quality of life. No patients developed FIX inhibitors, and there were no thromboembolic events or unexpected safety concerns. Nonacog beta pegol was also safe and effective in the perioperative setting. These findings show that nonacog beta pegol is highly effective, while also offering more convenient dosing than standard FIX products. Nonacog beta pegol represents a significant advance in the current context of treatment for hemophilia B, offering effective management across several treatment modalities and settings, and potentially easing the treatment burden for patients of all ages. Meanwhile, the development of novel treatment strategies, such as gene therapy, anti-tissue factor pathway inhibitor antibodies, and RNA interference therapy, may provide patients with additional therapeutic options, which would require reassessment of the role of EHL products in the future.

Keywords: long-acting FIX, PEGylated rFIX, extended half-life, prophylaxis

\section{Management issues in the treatment of hemophilia B}

Treatment strategies for hemophilia B generally focus on the administration of factor replacement therapy with either plasma-derived factor IX (pdFIX) or recombinant factor IX (rFIX) products. These products are administered intravenously, either ondemand (when bleeds occur) or as prophylaxis to prevent bleeds from occurring, as well as in the perioperative setting. ${ }^{1,2}$ Prophylaxis is the current standard of care for hemophilia treatment in developed countries. Compared with on-demand treatment, prophylaxis for patients with hemophilia has been shown to reduce bleeding frequency, prevent hemophilic arthropathy, and improve quality of life (QoL)..$^{3-5}$

Even so, prophylaxis with standard dosing regimens using unmodified FIX products does not enable sufficient factor activity to avoid bleeds altogether in some patients. ${ }^{6-8}$ Based on FIX half-life, prophylaxis with unmodified FIX concentrates is usually 
administered as two injections/week; however, dosing regimens need to be adjusted to the bleeding phenotype, and there are patients who require more intensive regimens. ${ }^{3}$ Furthermore, conventional prophylaxis is limited by the burden of multiple injections per week. Frequent injections are an obstacle to adherence in adolescents and adults and may be especially challenging in young children in whom venous access can be difficult. ${ }^{2,9-12}$

While patients rarely bleed with FIX activity trough levels $>1 \%$ of normal $(0.01$ of $1 \mathrm{IU} / \mathrm{mL})$, some patients continue to experience bleeds with troughs $>0.03 \mathrm{IU} / \mathrm{mL},{ }^{6}$ and patients with joint damage may require even higher FIX activity trough levels to prevent bleeding. ${ }^{13}$ In addition, a recent study by the US Centers for Disease Control and Prevention of male patients with mild and moderate hemophilia A or B, treated on-demand, reported that the target activity levels of $0.15 \mathrm{IU} / \mathrm{mL}$ are unlikely to prevent all joint bleeds. ${ }^{14}$ This highlights the need for replacement therapies that can provide higher factor levels, in a more mild range (0.05-0.40 IU/mL), which are not achieved with current standard FIX products.

To address many of these issues, several extended halflife (EHL) products have been developed for the treatment of hemophilia B. These EHL products require less frequent dosing than conventional FIX concentrates and, therefore, are attractive to both physicians and patients. Current data indicate that EHL FIX products will enable adequate FIX trough levels to be maintained with considerably fewer infusions per year. ${ }^{4,15}$

Various technologies have been utilized to extend the half-life of coagulation factors. ${ }^{2,16,17}$ This review provides an overview of the development of an EHL product that incorporates a polyethylene glycol (PEG) molecule to improve the clinical profile of standard FIX for the treatment of patients with hemophilia B. ${ }^{2}$

\section{Development of glycoPEGylated rFIX, a long-acting molecule for hemophilia B}

Nonacog beta pegol (N9-GP, Novo Nordisk A/S, Bagsværd, Denmark) is a recombinant, FIX protein produced by the site-specific covalent attachment of a $40 \mathrm{kDa}$ PEG moiety to prolong the half-life of conventional FIX (Figure 1). ${ }^{2}$ Upon activation of FIX at the site of injury, the activation peptide and the attached PEG molecule are cleaved off to yield native activated FIX. The rFIX protein backbone of nonacog beta pegol is identical in amino acid structure to currently available rFIX products and is expressed by Chinese

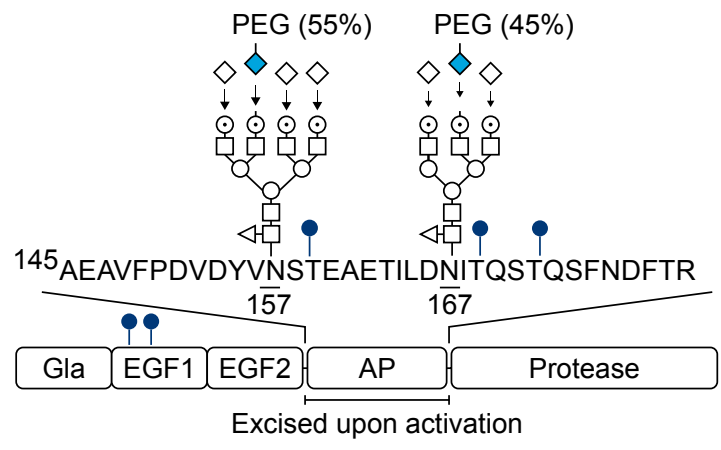

Figure I Domain structure of nonacog beta pegol.

Notes: Two N-linked glycans are uniformly present at AsnI57 and Asnl67 in the rFIX AP domain. These are predominantly core-fucosylated tri- and tetra-antennary complex structures composed of fucose $(\triangleleft), \mathrm{N}$-acetylglucosamine ( $\square$ ), mannose $(\bigcirc)$, galactose $(\odot)$, and sialic acid $(\diamond)$. Arrows indicate the enzymatic transfer of 40k-PEG-sialic acid to desialylated nonacog beta pegol and sialylation of remaining exposed galactoses. PEG is unequally distributed between the two $\mathrm{N}$-linked glycans, as shown in parentheses ( $55 \%$ and $45 \%$, respectively). Locations of identified O-linked carbohydrates are also shown $(\bullet)$. Reproduced with permission of American Society of Hematology. Østergaard H, Bjelke JR, Hansen L, et al. Prolonged half-life and preserved enzymatic properties of factor IX selectively PEGylated on native $\mathrm{N}$-glycans in the activation peptide. Blood. 20I I; I 18(8):2333-234I. Permission conveyed through the Copyright Clearance Center, Inc. ${ }^{2}$ Copyright 20I I, American Society of Hematology. Abbreviations: AP, activation peptide; PEG, polyethylene glycol; rFIX, recombinant factor IX.

hamster ovary cells under serum-free conditions to maximize consistency, homogeneity, and production capacity. ${ }^{18}$

Preclinical studies in normal rats revealed that nonacog beta pegol is excreted via both the kidneys and liver, ${ }^{19}$ and other animal studies have reported no adverse laboratory findings of known clinical relevance. ${ }^{20}$ Whether an observed presence of the PEG moiety in the choroid plexus in animal models has any long-term clinical impact is not yet known, but no adverse clinical, behavioral, or histopathological effects have been observed to date. ${ }^{21}$

The pharmacokinetics (PK), efficacy, and safety of nonacog beta pegol in previously treated adults, adolescents, and children have been assessed in the paradigm 1, 2, 3, 4 , and 5 clinical trials (Figure 2 and Table 1). Each trial enrolled previously treated patients (PTPs) with hemophilia B (FIX $\leq 0.02 \mathrm{IU} / \mathrm{mL}$ ), $\geq 50$ exposure days ( $\geq 150$ for adolescents and adults) to any FIX product, and no history of inhibitors ( $\geq 0.6$ Bethesda units).

The paradigm $1,2,3,4,5$, and 6 clinical trials are explained as follows:

1) paradigm 1 was the first-in-human dose, Phase I trial in patients with hemophilia B and investigated the safety and PK properties of a single intravenous (IV) dose of nonacog beta pegol (either 25, 50, or $100 \mathrm{U} / \mathrm{kg}$ ). ${ }^{18}$

2) paradigm 2 was a pivotal Phase III trial that assessed the safety, efficacy, and PK of nonacog beta pegol in PTPs aged 13-70 years with hemophilia B. ${ }^{22}$ 

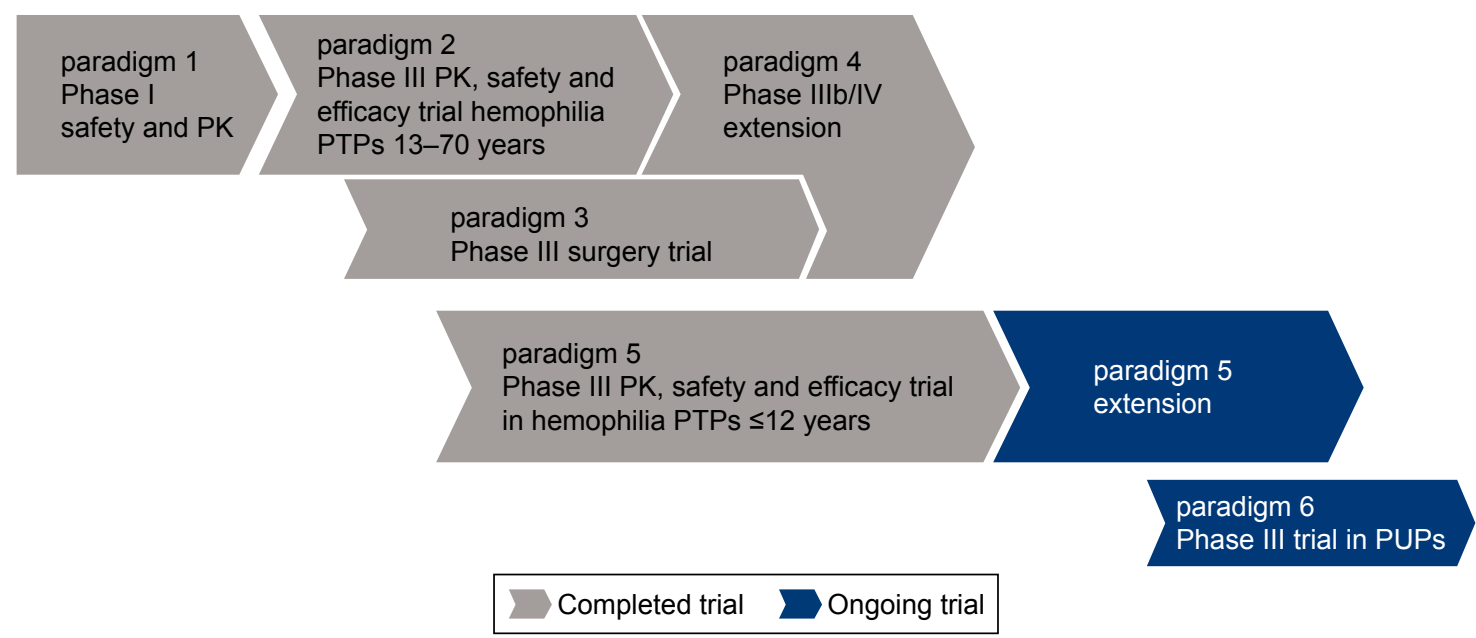

Figure 2 Overview of the paradigm clinical trial program.

Notes: ClinicalTrials.gov identifiers: NCT00956345, NCT0I333III, NCT0I386528, NCTOI3958I0, NCT0I467427, and NCT02 I4I074.

Abbreviations: PK, pharmacokinetics; PTPs, previously treated patients; PUPs, previously untreated patients.

3) paradigm 3 investigated the safety and perioperative efficacy of $80 \mathrm{IU} / \mathrm{kg}$ nonacog beta pegol in PTPs (13-70 years, $n=13$ ) with hemophilia $B$, who were scheduled to undergo major surgical procedures. ${ }^{23}$

4) paradigm 4 was an international extension trial investigating the safety and efficacy of nonacog beta pegol in patients who had previously participated in the paradigm 2 or paradigm 3 trials. ${ }^{24}$

5) paradigm 5 investigated the safety, efficacy, and PK of nonacog beta pegol for prophylaxis and treatment of bleeds in 25 young PTPs ( $\leq 12$ years) with hemophilia B. ${ }^{25}$

6) An ongoing Phase III trial, paradigm 6, is currently investigating the safety and efficacy of nonacog beta pegol in previously untreated patients. ${ }^{26}$

\section{Clinical pharmacology of glycoPEGylated rFIX}

FIX activity levels and PK were monitored throughout the paradigm clinical trial program; the findings have helped to establish the novel clinical characteristics of nonacog beta pegol and provide a basis for its potential use in multiple treatment modalities.

In the first-in-human dose trial, paradigm 1, the singledose PK of nonacog beta pegol showed a half-life of 93 hours, five times that of patients' previous product (either rFIX or pdFIX), offering the possibility of once-weekly prophylaxis (Figure 3). ${ }^{18}$ Incremental recovery was $94 \%$ higher than rFIX and $20 \%$ higher than pdFIX. Nonacog beta pegol also produced an increased area under the plasma concentration-time curve (AUC) relative to standard rFIX and pdFIX products. Furthermore, in the surgical trial, paradigm 3, FIX activity was maintained $>1 \mathrm{IU} / \mathrm{mL}$ for at least 24 hours following a single preoperative bolus injection, and none of the 13 patients required additional doses on the day of surgery. ${ }^{23}$

Prophylaxis with EHL products, such as nonacog beta pegol, offers fewer infusions and the prospect of increased trough levels. Time spent $<0.01 \mathrm{IU} / \mathrm{mL}$ trough has been shown to be proportional to the incidence of breakthrough bleeds (bleeding occurring between prophylactic factor infusions) in hemophilia A. ${ }^{27}$

In the pivotal Phase III trial (paradigm 2), nonacog beta pegol administered once weekly maintained FIX activity significantly $>0.01 \mathrm{IU} / \mathrm{mL}$, and the estimated mean FIX trough levels during the trial were $0.085 \mathrm{IU} / \mathrm{mL}$ for the $10 \mathrm{IU} / \mathrm{kg}$ arm and $0.273 \mathrm{IU} / \mathrm{mL}$ for the $40 \mathrm{IU} / \mathrm{kg}$ arm (Figure 4A). ${ }^{22}$ In the pediatric trial (paradigm 5), the estimated mean steady-state FIX trough levels were $0.153 \mathrm{IU} / \mathrm{mL}$ in patients aged $0-6$ years and $0.190 \mathrm{IU} / \mathrm{mL}$ in those aged $7-12$ years (Figure 4B). Steady-state trough levels were achieved after $\sim 4$ weeks of treatment. ${ }^{25}$

These findings show that patients receiving once-weekly prophylaxis with nonacog beta pegol remain in the mild hemophilia range $(0.05-0.40 \mathrm{IU} / \mathrm{mL})$ for most of the time.

A recent $\mathrm{PK}$ analysis by Tiede et $\mathrm{al}^{28}$ assessed patients who had received nonacog beta pegol $40 \mathrm{IU} / \mathrm{kg}$ while enrolled in paradigm 2 and paradigm 5. After single-dose administration, half-life was 85.1 hours in adults and adolescents vs 69.6 and 76.3 hours in children aged $0-6$ and $7-12$ years, respectively (Table 2). Incremental recovery for single-dose PK was lower for children of all ages vs adults and adolescents, whereas clearance per kilogram of body weight was higher. In adults and adolescents at steady state, the half-life 
Table I Overview of paradigm clinical trials

\begin{tabular}{|c|c|c|c|c|}
\hline Trial & Trial design & Treatment $^{\mathbf{a}}$ & $\begin{array}{l}\text { Number of dosed } \\
\text { patients }^{\mathrm{b}} \text { and actual } \\
\text { age ranges }\end{array}$ & $\begin{array}{l}\text { Patient clinical } \\
\text { status at baseline }\end{array}$ \\
\hline \multicolumn{5}{|c|}{ Previously treated patients } \\
\hline paradigm $1^{18}$ & $\begin{array}{l}\text { First-in-human dose trial } \\
\text { Phase I, multicenter, open-label, dose-escalation } \\
\text { trial evaluating safety and PK of three ascending } \\
\text { single-doses }\end{array}$ & $\begin{array}{l}25,50 \text {, or } 100 \mathrm{IU} / \mathrm{kg} \text { (single-dose } \\
\text { nonacog beta pegol) } \\
25,50 \text {, or } 100 \mathrm{IU} / \mathrm{kg} \text { (previous FIX } \\
\text { product, single-dose) }\end{array}$ & $\begin{array}{l}\text { Total: } 16 \text { adult patients } \\
(2 \mathrm{I}-55 \text { years }) \\
\text { PK: I } 5 \text { patients }\end{array}$ & \\
\hline paradigm $2^{22}$ & $\begin{array}{l}\text { Pivotal trial } \\
\text { Phase III, multicenter, single-blind,c } \\
\text { noncontrolled, randomized trial evaluating } \\
\text { safety, efficacy, and PK in routine prophylaxis } \\
\text { and treatment of bleeds } \\
\text { Three treatment arms: } 10 \text { or } 40 \mathrm{IU} / \mathrm{kg} \text { once- } \\
\text { weekly prophylaxis for } 52 \text { weeks or on-demand } \\
\text { treatment for } 28 \text { weeks }\end{array}$ & $\begin{array}{l}\text { Prophylaxis: } \mathrm{I} 0 \mathrm{IU} / \mathrm{kg} \text { or } 40 \mathrm{IU} / \mathrm{kg} \\
\text { once weekly } \\
\text { Treatment of bleeds: mild and } \\
\text { moderate bleeds were treated with } \\
\text { injection(s) of } 40 \mathrm{IU} / \mathrm{kg} \text {; severe } \\
\text { bleeds were treated with } 80 \mathrm{IU} / \mathrm{kg}\end{array}$ & $\begin{array}{l}\text { Total: } 74 \text { adolescent } \\
\text { or adult patients } \\
\text { (13-65 years) } \\
\text { Prophylaxis: } 59 \text { patients } \\
\text { On-demand: } 15 \text { patients } \\
\text { PK (three batches): } \\
16 \text { patients }\end{array}$ & $\begin{array}{l}\text { Arthropathy: } 64.9 \% \\
\text { Target joints: } 54.1 \%\end{array}$ \\
\hline paradigm $3^{23}$ & $\begin{array}{l}\text { Surgery trial } \\
\text { Phase III, multicenter, open-label, noncontrolled } \\
\text { trial evaluating efficacy and safety during major } \\
\text { surgical procedures }\end{array}$ & $\begin{array}{l}\text { Preoperative dose: } 80 \mathrm{IU} / \mathrm{kg} \text { on the } \\
\text { day of surgery } \\
\text { Postoperative dose }(\mathrm{s}) \text { : } \\
\text { recommended to give two doses } \\
\text { of } 40 \mathrm{IU} / \mathrm{kg} \text { within the first } 6 \text { days } \\
\text { after surgery }\end{array}$ & $\begin{array}{l}\text { Total: } 13 \text { adolescent } \\
\text { or adult patients } \\
\text { ( } 15-56 \text { years })\end{array}$ & \\
\hline paradigm $4^{24}$ & $\begin{array}{l}\text { Extension trial to paradigm } 2 \text { and } 3 \\
\text { Phase III, multicenter, open-label, noncontrolled } \\
\text { trial evaluating long-term safety and efficacy in } \\
\text { routine prophylaxis and treatment of bleeds } \\
\text { Four treatment arms: } 10 \text { or } 40 \mathrm{IU} / \mathrm{kg} \text { once- } \\
\text { weekly prophylaxis, } 80 \mathrm{IU} / \mathrm{kg} \text { once every } \\
\text { second week prophylaxis, or on-demand } \\
\text { treatment. Free choice between available } \\
\text { treatment arms and switching of treatment arm } \\
\text { during the trial was allowed }\end{array}$ & $\begin{array}{l}\text { Prophylaxis: } \mathrm{I} 0 \text { or } 40 \mathrm{IU} / \mathrm{kg} \text { once } \\
\text { weekly, or } 80 \mathrm{IU} / \mathrm{kg} \text { once every } \\
\text { second week } \\
\text { Treatment of bleeds: mild and } \\
\text { moderate bleeds were treated with } \\
\text { injection(s) of } 40 \mathrm{IU} / \mathrm{kg} \text {; severe } \\
\text { bleeds were treated with } 80 \mathrm{IU} / \mathrm{kg}\end{array}$ & $\begin{array}{l}\text { Total: } 7 \text { I adolescent } \\
\text { or adult patients } \\
\text { (14-66 years) }\end{array}$ & $\begin{array}{l}\text { Arthropathy: } 63.4 \% \\
\text { Target joints: } 49.3 \%\end{array}$ \\
\hline paradigm $5^{25}$ & $\begin{array}{l}\text { Pediatric trial } \\
\text { Phase III, multicenter, open-label, } \\
\text { noncontrolled trial evaluating safety, efficacy, } \\
\text { and PK in routine prophylaxis and treatment of } \\
\text { breakthrough bleeds } \\
\text { The trial contained a main phase of } 52 \text { weeks, } \\
\text { followed by an ongoing extension phase. One } \\
\text { treatment arm with } 40 \mathrm{IU} / \mathrm{kg} \text { once-weekly } \\
\text { prophylaxis }\end{array}$ & $\begin{array}{l}\text { Prophylaxis: } 40 \mathrm{IU} / \mathrm{kg} \text { once weekly. } \\
\text { Treatment of bleeds: mild and } \\
\text { moderate bleeds were treated with } \\
\text { injection(s) of } 40 \mathrm{IU} / \mathrm{kg} \text {; severe } \\
\text { bleeds were treated with } 80 \mathrm{IU} / \mathrm{kg}\end{array}$ & $\begin{array}{l}\text { Total: } 25 \text { pediatric } \\
\text { patients ( } I-12 \text { years) } \\
\text { PK: } 25 \text { patients } \\
22 \text { patients continued } \\
\text { into the extension } \\
\text { phase of the trial }\end{array}$ & $\begin{array}{l}\text { Arthropathy: } 8.0 \% \\
\text { Target joints: } 8.0 \%\end{array}$ \\
\hline \multicolumn{5}{|c|}{ Previously untreated patients } \\
\hline paradigm $6^{26}$ & $\begin{array}{l}\text { Trial in previously untreated patients } \\
\text { Phase III, multicenter, open-label, single-arm, } \\
\text { noncontrolled trial evaluating safety and efficacy } \\
\text { in prophylaxis and treatment of breakthrough } \\
\text { bleeds in previously untreated patients }\end{array}$ & $\begin{array}{l}\text { Prophylaxis: } 40 \mathrm{lU} / \mathrm{kg} \text { once weekly } \\
\text { Treatment of bleeds: mild and } \\
\text { moderate bleeds were treated with } \\
\text { injection(s) of } 40 \mathrm{IU} / \mathrm{kg} \text {; severe } \\
\text { bleeds were treated with } 80 \mathrm{IU} / \mathrm{kg}\end{array}$ & $\begin{array}{l}\text { The planned number of } \\
\text { patients to be exposed } \\
\text { is } 50\end{array}$ & \\
\hline
\end{tabular}

Notes: ${ }^{a}$ Treatment with nonacog beta pegol unless specified otherwise. Additional doses for the treatment of bleeds could be given at the investigator's discretion. ${ }^{b}$ All patients had hemophilia B with an FIX activity of $\leq 0.02 \mathrm{IU} / \mathrm{mL}$. PPatients on prophylaxis did not know whether they were randomized to the $10 \mathrm{IU} / \mathrm{kg}$ or the $40 \mathrm{IU} / \mathrm{kg}$ once-weekly arm. This information was also concealed from the investigator; however, as the investigator was able to measure FIX activity levels during the trial, they could potentially become unblinded.

Abbreviations: FIX, factor IX; PK, pharmacokinetics.

of nonacog beta pegol was 111 hours; trough FIX activity was $0.31 \mathrm{IU} / \mathrm{mL}$ at 168 hours post dose (ie, prior to receiving the next dose) with once-weekly nonacog beta pegol $40 \mathrm{IU} / \mathrm{kg}$. There were no apparent differences in single-dose
PK parameters across race groups for all ages or between normal-weight (body mass index [BMI]: 18.5-24.9 kg/m²; $\mathrm{n}=5$ ) and overweight (BMI: $\geq 25 \mathrm{~kg} / \mathrm{m}^{2} ; \mathrm{n}=4$ ) adults and adolescents. As expected, children exhibited lower plasma 


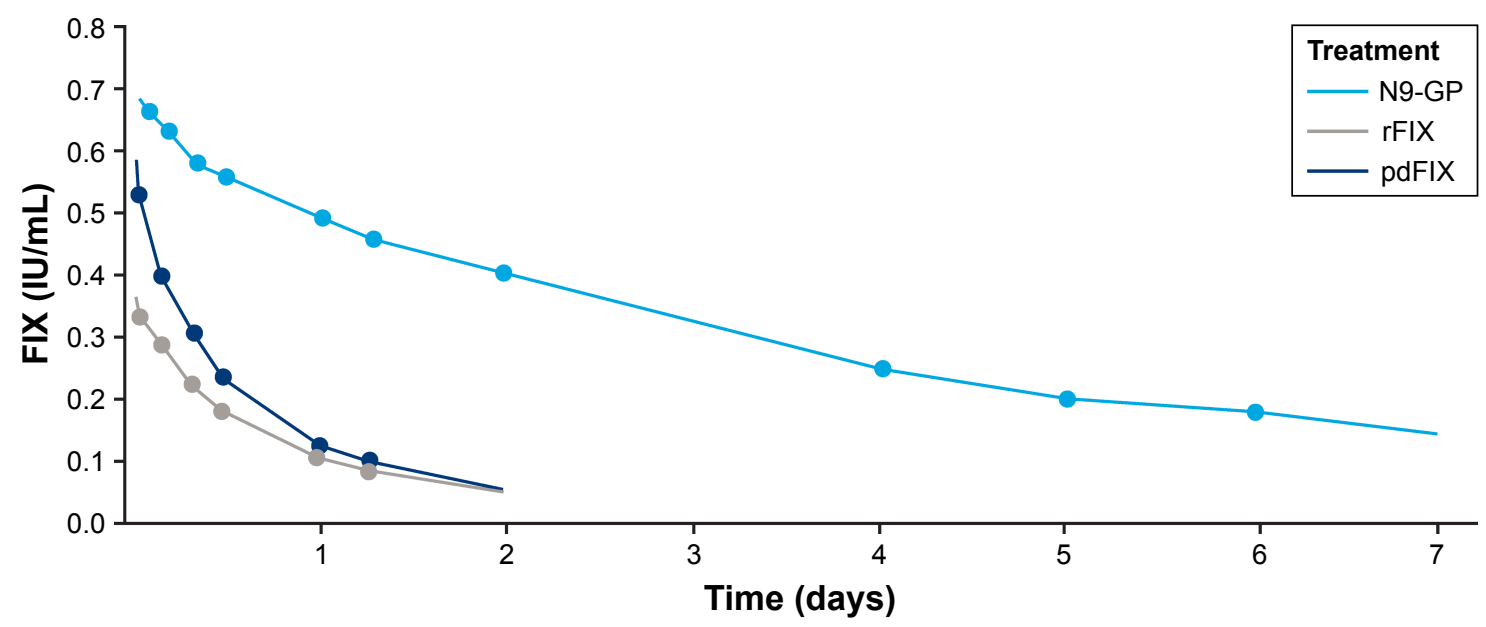

Figure 3 Estimated mean FIX activity profiles adjusted to a dose of $50 \mathrm{lU} / \mathrm{kg}$ nonacog beta pegol.

Abbreviations: FIX, factor IX; N9-GP, nonacog beta pegol; pdFIX, plasma-derived factor IX; rFIX, recombinant factor IX.
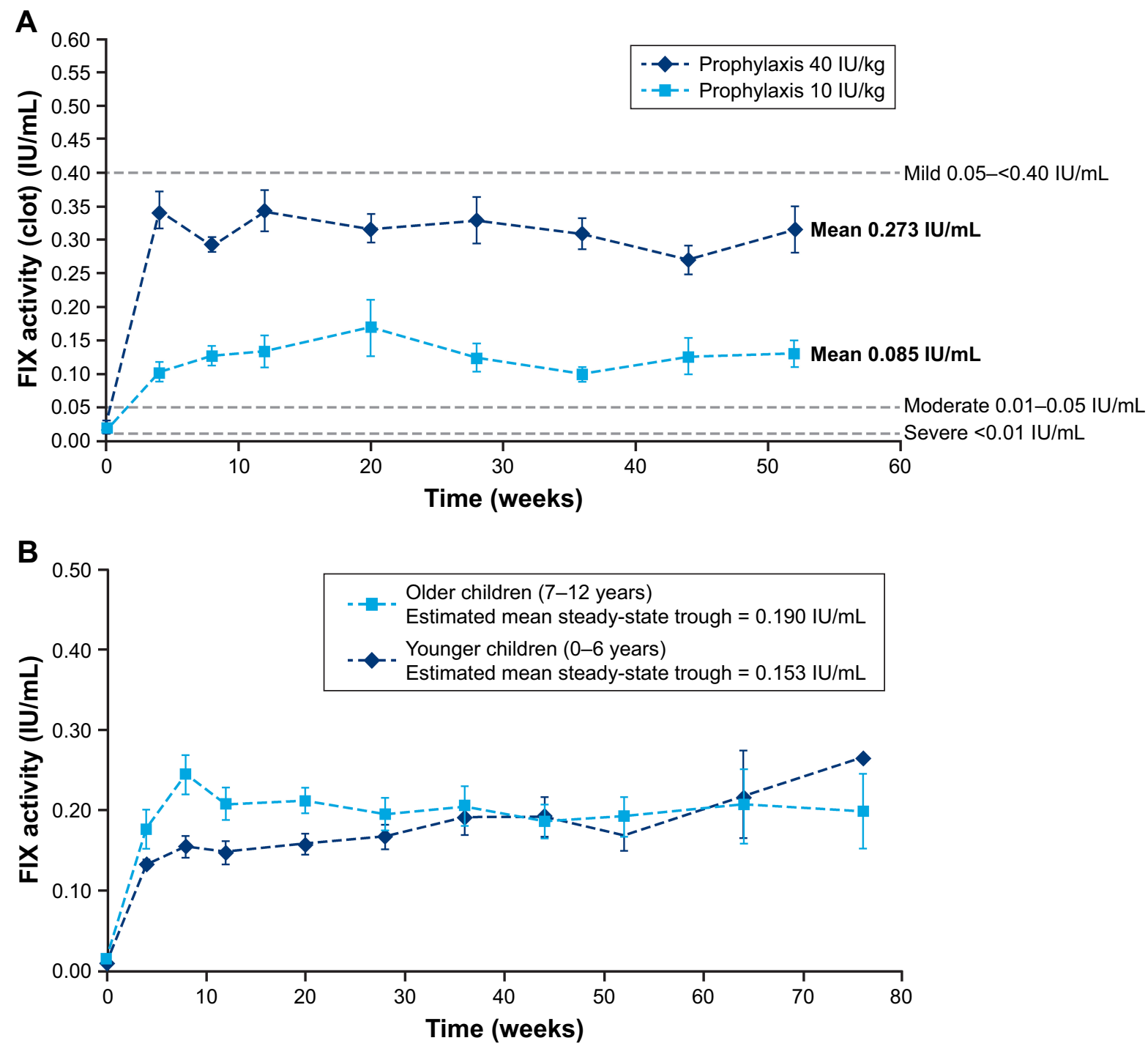

Figure 4 Mean steady-state trough FIX activity with once-weekly nonacog beta pegol during (A) paradigm 2 and (B) paradigm 5.

Notes: Mean ( \pm standard error of the mean) steady-state FIX activity (IU/mL) determined by a one-stage clotting assay in predose blood samples collected at clinical visits during each trial. Analyses were performed at a central laboratory, using a product-specific reference standard for calculation of the FIX activity. Abbreviation: FIX, factor IX. 
Table 2 Summary of PK parameters based on $40 \mathrm{IU} / \mathrm{kg}$ dosing

\begin{tabular}{|c|c|c|c|c|}
\hline \multirow[t]{2}{*}{ PK parameter } & \multicolumn{2}{|c|}{ Children (single-dose PK only) $^{\mathrm{a}}$} & \multicolumn{2}{|c|}{ Adults/adolescents $^{a}$} \\
\hline & $\begin{array}{l}0-6 \text { years } \\
(n=12)\end{array}$ & $\begin{array}{l}7-12 \text { years } \\
(n=13)\end{array}$ & $\begin{array}{l}\text { Single-dose } \\
(n=9)\end{array}$ & $\begin{array}{l}\text { Steady-state } \\
(n=9)\end{array}$ \\
\hline Incremental recovery $\left(\mathrm{IR}_{30 \mathrm{~min}}\right), \mathrm{IU} / \mathrm{mL} / \mathrm{IU} / \mathrm{kg}$ & $0.015(7.3)^{b}$ & $0.016(16.2)$ & $0.022(14.5)$ & $0.019(21.1)$ \\
\hline Clearance, $\mathrm{mL} / \mathrm{h} / \mathrm{kg}$ & $0.8(\mid 3.0)$ & $0.6(21.9)$ & $0.4(20.4)$ & $0.4(12.3)$ \\
\hline Half-life, hours & $69.6(15.8)$ & $76.3(25.5)$ & $85.1(21.8)$ & $110.8(11.8)$ \\
\hline FIX activity 168 hours post dose, ${ }^{\mathrm{c}} \mathrm{IU} / \mathrm{mL}$ & $0.084(16.3)$ & $0.109(18.9)$ & $0.16(34.4)$ & $0.3 I^{d}(I 7.3)$ \\
\hline $\mathrm{AUC}_{(0-\mathrm{inf})}, \mathrm{IU} \times$ hours $/ \mathrm{mL}$ & $46.2(14.1)$ & $56.2(19.1)$ & $86.9(22.3)$ & $141.3(17.4)$ \\
\hline
\end{tabular}

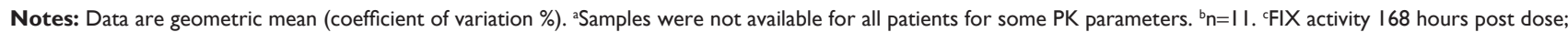
values based on $n=11,12,8$, and 8, respectively. ${ }^{\circledR}$ Steady-state value corresponding to predosing for next dose, ie, trough level.

Abbreviations: $\mathrm{AUC}_{(0-\text { inf })}$, area under the concentration-time curve from time zero to infinity; FIX, factor $I X ; \mathbb{R}_{30}$ min, incremental recovery at $t=30$ minutes; $P K$, pharmacokinetic.

FIX activity levels and incremental recoveries vs adults and adolescents.

Even so, all measured FIX activity levels were higher than data generated for standard FIX products. The monoexponential decay in plasma FIX activity (which differs from other long-acting products $)^{8}$ favorably supports onceweekly administration of nonacog beta pegol in patients with hemophilia B. ${ }^{28}$

These findings suggest that nonacog beta pegol, as an EHL FIX product, offers a significant pharmacologic improvement over standard factor replacement.

\section{Clinical efficacy of glycoPEGylated rFIX}

In addition to ongoing pharmacologic assessment, the clinical efficacy of nonacog beta pegol was explored in paradigm 2 , paradigm 3, paradigm 4 (Phase IIIb, extension of paradigm 2 and paradigm 3 ), and paradigm 5 (Table 1).

\section{Prophylaxis}

The prophylactic efficacy of nonacog beta pegol was primarily established in paradigm 2 in PTPs aged 13-70 years with hemophilia B. ${ }^{22}$ Patients elected to receive either on-demand treatment (nonacog beta pegol $40 \mathrm{IU} / \mathrm{kg}[\mathrm{n}=15]$ ) for 28 weeks or one of two randomized prophylaxis regimens (nonacog beta pegol $10 \mathrm{IU} / \mathrm{kg}[\mathrm{n}=30]$ or $40 \mathrm{IU} / \mathrm{kg}$ [n=29], once weekly) for 52 weeks. Patients were blinded to the prophylaxis dose throughout the trial, but investigators could become unblinded if FIX activity needed to be measured locally. Prophylactic treatment with nonacog beta pegol $40 \mathrm{IU} / \mathrm{kg}$ once weekly resulted in a median annualized bleeding rate (ABR) of 1.0 bleed/patient/year (mean [95\% CI]: 1.84 [1.26, 2.70]), significantly lower than that achieved for the $10 \mathrm{IU} / \mathrm{kg}$ prophylaxis (median: 2.9 ; mean [95\% CI]: $4.56[3.01,6.90]$ ) and on-demand (median: 15.6) treatment arms (Table 3).

Patients who had participated in and completed either the paradigm 2 or paradigm 3 trials were eligible for enrollment in paradigm $4 .{ }^{24}$ This was an open-label, nonrandomized, multicenter trial, which initially allocated patients to one of three nonacog beta pegol treatment arms according to the original protocol (Table 1). Choice of treatment regimen was agreed between the patient and investigator at the start of the trial, but could be changed at any time due to clinical manifestations and investigator recommendations.

Sixteen patients had moved from on-demand treatment or $10 \mathrm{IU} / \mathrm{kg}$ prophylaxis over to the $40 \mathrm{IU} / \mathrm{kg}$ prophylaxis arm, meaning that the number of patients in the $40 \mathrm{IU} / \mathrm{kg}$ arm of paradigm 4 was almost double that of paradigm 2 . While paradigm 4 primarily focused on safety, the observed efficacy findings were consistent with those observed in paradigm 2 (Table 3). Median ABR for patients in the $40 \mathrm{IU} / \mathrm{kg}$ prophylaxis arm was maintained at 1.0 , while that for the $10 \mathrm{IU} / \mathrm{kg}$ prophylaxis treatment arm had reduced further to 1.4 (mean [95\% CI]: $1.84[1.00,3.38]$ ) given that the remaining patients in that arm appeared to be low bleeders.

In addition, post hoc analyses of patients with target joints ( $\geq 3$ spontaneous bleeds in a given joint within the previous 6 months) at baseline in paradigm 2 and paradigm 4 demonstrated that once-weekly prophylaxis with nonacog beta pegol $40 \mathrm{IU} / \mathrm{kg}$ may provide effective management of target joint bleeds. ${ }^{29}$ Overall, $49 \%$ of the patients enrolled in paradigm 4 had target joints at baseline and $63 \%$ had arthropathy (Table 1), which may have contributed to the overall number of bleeds. By the end of paradigm 2, 90\% of the target joints had resolved among patients receiving this regimen; this increased to $100 \%$ after an additional year of treatment in paradigm 4.

The efficacy of nonacog beta pegol in children with hemophilia B was investigated in paradigm 5 , which enrolled 25 pediatric PTPs ( $\leq 12$ years). ${ }^{25}$ Patients were stratified into two age groups (0-6 and 7-12 years) and received onceweekly prophylaxis with nonacog beta pegol $40 \mathrm{IU} / \mathrm{kg}$ for 


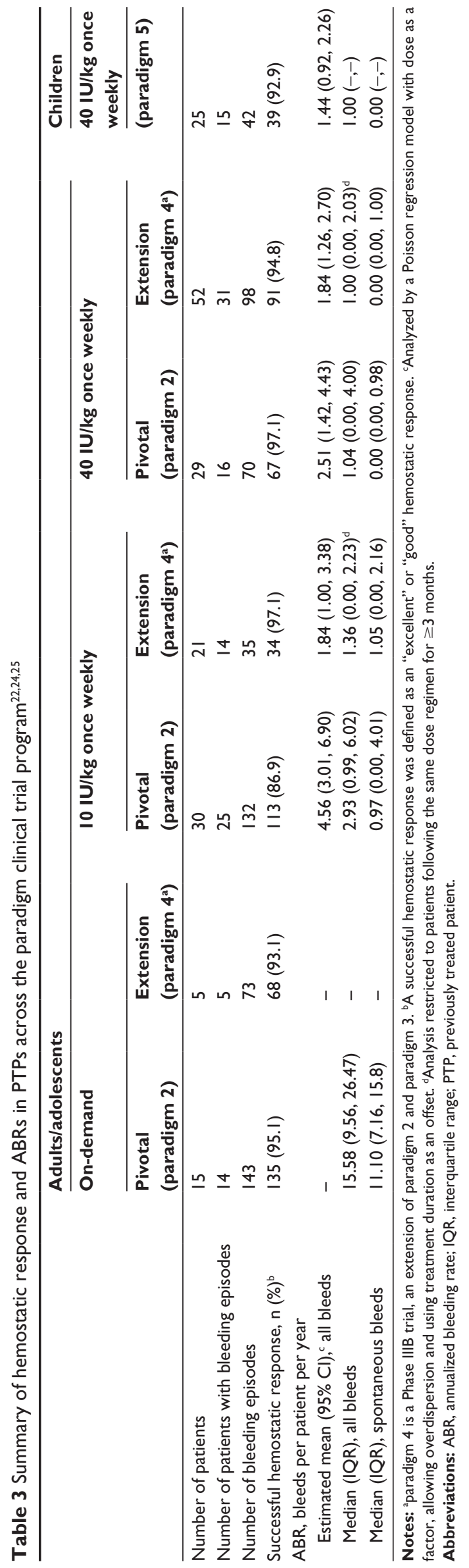

an initial 52 weeks, followed by an ongoing extension trial phase. Following the main study phase, the median ABR was 1.0 (mean [95\% CI]: $1.44[0.92,2.26]$ ) (spontaneous 0.0 ) in the total population (Table 3 ).

A total of 22 patients entered the subsequent extension phase of paradigm 5: 11 patients aged 0-6 years and 11 aged 7-12 years. ${ }^{30}$ By the planned interim analysis cut off date of January 1, 2016, in-trial exposure days had totaled 3,412 (136.5 per patient), and the mean treatment period per patient was 2.55 years. Overall, 69 bleeds were reported in 19 patients, of which 37 bleeds occurred in 15 patients during the main phase (mean treatment period: 0.97 years/patient), and 32 bleeds occurred in 11 patients during the extension phase (1.80 years/patient). Most bleeds (36 [60.0\%]) occurred $>4$ days after the last nonacog beta pegol dose, and $24(40.0 \%)$ of these bleeds were traumatic. The estimated mean ABR was 1.08 overall, 0.61 in patients aged $0-6$ years, and 1.48 in those aged $7-12$ years. ${ }^{30}$ Estimated mean ABRs progressively decreased in each successive 6-month period during the trial.

\section{Treatment of bleeds}

The episodic administration of nonacog beta pegol, whether for patients in a designated on-demand treatment arm or as breakthrough bleed treatment for patients on prophylaxis, was also investigated throughout the paradigm clinical trial program.

A total of 345 bleeding episodes (in 55 [74\%] patients) were treated with nonacog beta pegol in paradigm 2 (202 in prophylaxis patients and 143 in patients receiving ondemand treatment); median ABR for patients in the ondemand treatment arm was 15.6. ${ }^{22}$ Approximately two thirds $(65.8 \%)$ of all bleeds were spontaneous, and the majority of bleeds were in joints (78.5\%). The overall success rate for the treatment of bleeds was $92 \%$ (responses defined as either "excellent" or "good"; ie, [abrupt/noticeable] pain relief and/or [clear] improvement in [objective] signs of bleeding within 8 hours after a single injection). Only one severe bleeding episode was reported (in the knee joint of a patient receiving $10 \mathrm{IU} / \mathrm{kg}$ prophylaxis); following ondemand treatment with nonacog beta pegol $80 \mathrm{IU} / \mathrm{kg}$, the hemostatic response was rated as "excellent". By the end of paradigm 4, the overall success rate for the treatment of bleeds (including breakthrough bleeds) had increased to $94.6 \% .^{24}$

In paradigm 5, bleeds were treated with an overall success rate of $92.9 \%,{ }^{25}$ which has remained stable during the extension phase of the trial $(92.8 \%))^{30}$ There was no on-demand treatment arm in paradigm 5 . 


\section{Surgery}

The use of nonacog beta pegol in the surgical setting was evaluated in paradigm 3, which investigated the perioperative efficacy of nonacog beta pegol $80 \mathrm{IU} / \mathrm{kg}$ in PTPs (13-70 years, $n=13$ ) with hemophilia $B$, who were scheduled to undergo major surgical procedures. ${ }^{23}$ Of the 13 patients, nine had major orthopedic surgery and four had major nonorthopedic surgery.

Nonacog beta pegol treatment resulted in $100 \%$ hemostatic success rate in all patients during major surgeries. The hemostatic effect of nonacog beta pegol was rated as "excellent" in $10(76.9 \%)$ and "good" in three (23.1\%) of the surgeries. A single preoperative dose of nonacog beta pegol $80 \mathrm{IU} / \mathrm{kg}$ maintained FIX activity at the requisite level throughout the surgery with no additional doses required. Postoperatively, a median of two additional doses of $40 \mathrm{IU} / \mathrm{kg}$ were required during the first week, while a median of 1.5 additional doses were administered the following week.

The risk of surgery-related bleeding has been reduced by standard FIX products, but comparisons with nonacog beta pegol or EHL products in the perioperative setting are limited by the relative scarcity of literature on bleeding risks in patients with hemophilia B. ${ }^{31-34}$ Moreover, there is great variability in defining bleeding risk and a lack of robust evidence on surgical outcomes. ${ }^{34}$ Nevertheless, perioperative use of nonacog beta pegol requires lower consumption and fewer injections than that reported for standard FIX products. ${ }^{23}$

\section{Safety and tolerability in the clinical use of glycoPEGylated rFIX}

Across all trials in the paradigm clinical trial program, 115 male patients (including 25 children aged $1-12$ years) were exposed to nonacog beta pegol. ${ }^{35}$ Total exposure time was 205 years, and the longest trial participation was 3.75 years. No patients developed FIX inhibitors ( $\geq 0.6$ Bethesda units) or reported thromboembolic events.

In total, 824 adverse events (AEs) were reported, the majority of which were mild in severity. Following evaluation of all AEs, hypersensitivity, pruritus, and injection site reactions were considered AEs possibly related to nonacog beta pegol, reported in one, three, and four patients, respectively. ${ }^{35}$ One fatality was recorded (hepatocellular carcinoma), but judged unlikely to be related to nonacog beta pegol.

Fourteen serious AEs occurred in 12 patients; all except one were judged unlikely to be related to nonacog beta pegol. ${ }^{35}$ The event judged as probably related to nonacog beta pegol was a severe hypersensitivity/allergic reaction in which the patient was subsequently treated with antihistamine and IV steroids. ${ }^{18}$ The patient fully recovered and went on to receive his previous pdFIX without any signs of inhibitor development or complications before he was withdrawn from the trial. Other serious AEs, judged unlikely to be related to nonacog beta pegol, included hip fracture, skin ulcer, retroperitoneal hematoma, abdominal pain, food poisoning, and viral upper respiratory tract infection.

Long-term exposure to the PEG moiety, relating to antibody production, accumulation, and long-term toxicity, especially in children, is a matter of discussion among some clinicians. In nonclinical studies, higher exposure to other PEGylated biologics has been shown to result in PEG accumulation and vacuolation in renal cells, neurons, and the choroid plexus, but there is no evidence of any cellular damage or dysfunction. ${ }^{36}$ These observations are thought to be largely dependent on specific conditions such as species, PEG moiety size, duration of exposure, and the dose. In children, it is recommended that the risk of vacuolation and accumulation is assessed for PEG sizes $>40 \mathrm{kDa}$; given that the PEG moiety in nonacog beta pegol is $40 \mathrm{kDa}$, the risk may be lower. ${ }^{37}$

Blood samples were collected across the paradigm clinical trials to assess anti-nonacog beta pegol antibodies and anti-FIX antibodies and (in paradigm 5) to indirectly screen for anti-PEG antibodies. No patients developed binding antibodies against nonacog beta pegol, FIX, or PEG, except for two patients in paradigm 4 who developed transient binding antibodies to nonacog beta pegol; however, these were of the lowest possible titer and did not crossreact to rFIX. Furthermore, the PK profiles obtained for these two patients did not indicate any inhibitory effects.

Overall, no AEs related to the PEG moiety have been observed in clinical or nonclinical studies of nonacog beta pegol. ${ }^{21,35,38}$ Moreover, no systematic changes over time were seen for any hematologic, hepatic, or renal parameters. While neurological function was not specifically assessed in the paradigm clinical program, there were no new safety signals indicative of neurologic adverse reactions or anything indirectly suggesting developmental concerns in pediatric patients exposed to nonacog beta pegol. Long-term postmarketing data in humans with nonacog beta pegol may help to alleviate these concerns further.

\section{Patient-focused perspectives}

The paradigm clinical program also assessed the impact of nonacog beta pegol once-weekly prophylaxis on patientreported outcomes. 
In paradigm 2, health-related QoL (HRQoL) was assessed using the EuroQoL-5 dimensions visual analog scale (EQ-5D VAS) score. ${ }^{22}$ In the $40 \mathrm{IU} / \mathrm{kg}$ prophylaxis group, HRQoL assessed by EQ-5D VAS was markedly improved from a median score of 75 (range: $35-100$ ) at trial entry to 90 (range: 60-100) at the end of the trial. By the end of the trial, fewer patients reported problems in the "Mobility" and "Pain/ Discomfort" EQ-5D domains. ${ }^{39}$ These findings remained stable during the extension trial, paradigm $4 .{ }^{39}$

Hemophilia-specific HRQoL was also assessed in the paradigm 2 and paradigm 4 trials, using the hemophilia adults QoL (HAEM-A-QOL) questionnaire. ${ }^{39}$ In paradigm 2, the prophylaxis $40 \mathrm{IU} / \mathrm{kg}$ arm reported significant improvements for total HAEM-A-QOL score $(-6.4 \pm 8.5, P=0.017)$ and three key domain scores: "Feeling" $(-15.2 \pm 18.3$; $P=0.010)$, "Sport" $(-15.3 \pm 19.0 ; P=0.020)$, and "Partnership" (-9.6 $\pm 15.5 ; P=0.031)$. In paradigm 4 , patients receiving prophylaxis with nonacog beta pegol $10 \mathrm{IU} / \mathrm{kg}$, who switched to the $40 \mathrm{IU} / \mathrm{kg}$ regimen, showed significant improvements in total HAEM-A-QOL score $(-12.5 \pm 8.7$; $P=0.016)$ and the "Physical Health" domain $(-23.1 \pm 14.4$; $P=0.016)$.

\section{Conclusion, place in therapy}

Nonacog beta pegol, a novel EHL product, represents a significant advance in the management of hemophilia B, potentially easing the burden of treatment for patients of all ages and providing an effective option across several treatment modalities and settings.

The paradigm clinical trial development program has demonstrated that once-weekly prophylactic treatment of PTPs with nonacog beta pegol $40 \mathrm{IU} / \mathrm{kg}$ results in a low bleed rate (effective prophylactic coverage with median ABR of 1.0 across all ages),,$^{22,24,25}$ improved joint status ( $90 \%$ of target joints no longer classified as target joints), ${ }^{29}$ and HRQoL, including overall HAEM-A-QOL score and key domain scores ("Feeling", "Sport", and "Partnership"). ${ }^{39}$

The efficacy of nonacog beta pegol is high while offering a more convenient infusion interval than conventional FIX therapy. ${ }^{22}$ Nonacog beta pegol is also safe and effective in the perioperative setting, with reduced factor consumption and injection frequency compared with that of standard FIX products. $^{23}$

However, patient/clinician choice of treatment, especially when switching products, is driven by a multitude of factors, including cost, tolerability, novel therapies, administration means, logistic considerations, familiarity, and a patient's lifestyle and degree of physical activity. ${ }^{40}$
Once-weekly dosing will likely be sufficient for the vast majority of patients, and molecules with sustained activity may offer prompt relief of pain and rescue of joint function, resulting in improved hemostatic efficacy and reduced arthropathy. ${ }^{41}$ Patients who experience frequent bleeds or who lead active lifestyles may require EHL products that provide higher factor trough and peak levels. ${ }^{42}$ Conversely, given that clinical trials of nonacog beta pegol included patients with moderate hemophilia $(\leq 0.02 \mathrm{IU} / \mathrm{mL}$ FIX activity), for whom there is limited evidence on disease management, EHL products may be beneficial for a subset of moderate patients who also need to maintain high trough levels. Nonetheless, it remains to be seen whether EHL products are able to meet the wider need for an easy-to-use treatment that optimizes adherence and compliance in a real-world setting.

Economic considerations will also be important in the uptake and adoption of EHL products by payers and other reimbursement bodies. Evaluating the full spectrum of the benefits of EHL over standard FIX products in relation to their costs will be vital.

Moreover, in future, the role of EHL factor replacement therapies will need to be reassessed as novel treatment strategies, which are currently in development, become available, such as gene therapy, anti-tissue factor pathway inhibitor antibodies, and RNA interference therapy. ${ }^{43-46}$

A pertinent question, however, will be the relevance of these new modalities to hemophilia B treatment in light of the efficacy of FIX EHL products. Ultimately, when devising therapeutic regimens, physicians will need to balance different patient requirements, the number of infusions, factor trough levels, and the cost of therapy, as well as patient expectations.

\section{Acknowledgment}

Safeer Mughal of PAREXEL, a medical writer supported by funding from Novo Nordisk A/S, provided drafts and editorial assistance to the authors during preparation of this manuscript.

\section{Disclosure}

E Santagostino has acted as an advisor or speaker for Bayer, Bioverativ, CSL Behring, Grifols, Kedrion, Novo Nordisk, Octapharma, Pfizer, Roche, Shire, and SOBI. ME Mancuso has acted as a consultant/advisor/speaker for Baxalta/Shire, Bayer HealthCare, CSL Behring, Kedrion, Novo Nordisk, Octapharma, Pfizer, Roche, and SOBI/Biogen. The authors report no other conflicts of interest in this work. 


\section{References}

1. Franchini M, Frattini F, Crestani S, Sissa C, Bonfanti C. Treatment of hemophilia B: focus on recombinant factor IX. Biologics. 2013;7: 33-38.

2. Østergaard H, Bjelke JR, Hansen L, et al. Prolonged half-life and preserved enzymatic properties of factor IX selectively PEGylated on native N-glycans in the activation peptide. Blood. 2011;118(8):2333-2341.

3. Srivastava A, Brewer AK, Mauser-Bunschoten EP, et al; Treatment Guidelines Working Group on Behalf of The World Federation of Hemophilia. Guidelines for the management of hemophilia. Haemophilia. 2013;19(1):e1-e47.

4. Carcao M. Changing paradigm of prophylaxis with longer acting factor concentrates. Haemophilia. 2014;20(suppl 4):99-105.

5. Franchini M, Frattini F, Crestani S, Bonfanti C. Haemophilia B: current pharmacotherapy and future directions. Expert Opin Pharmacother. 2012;13(14):2053-2063.

6. Ahnström J, Berntorp E, Lindvall K, Björkman S. A 6-year follow-up of dosing, coagulation factor levels and bleedings in relation to joint status in the prophylactic treatment of haemophilia. Haemophilia. 2004; 10(6):689-697.

7. Jackson SC, Yang M, Minuk L, et al. Patterns of tertiary prophylaxis in Canadian adults with severe and moderately severe haemophilia B. Haemophilia. 2014;20(3):e199-e204.

8. Powell JS, Pasi KJ, Ragni MV, et al. Phase 3 study of recombinant factor IX Fc fusion protein in hemophilia B. $N$ Engl J Med. 2013; 369(24):2313-2323.

9. Hacker MR, Geraghty S, Manco-Johnson M. Barriers to compliance with prophylaxis therapy in haemophilia. Haemophilia. 2001;7(4): 392-396.

10. Thornburg CD, Pipe SW. Adherence to prophylactic infusions of factor VIII or factor IX for haemophilia. Haemophilia. 2006;12(2): 198-199.

11. de Moerloose P, Urbancik W, van den Berg HM, Richards M. A survey of adherence to haemophilia therapy in six European countries: results and recommendations. Haemophilia. 2008;14(5):931-938.

12. Saxena K. Barriers and perceived limitations to early treatment of hemophilia. J Blood Med. 2013;4:49-56.

13. Björkman S. Prophylactic dosing of factor VIII and factor IX from a clinical pharmacokinetic perspective. Haemophilia. 2003;9(suppl 1): 101-8; discussion 109-110.

14. Soucie M, Monahan PE, Mazepa M, Kulkarni R, Konkle BA; U.S. Hemophilia Treatment Center Network. Relations between factor activity level and joint bleeding in a large cohort of males with mild and moderate hemophilia in the United States. The 25th Congress of the International Society on Thrombosis and Haemostasis. 2015. Toronto, ON, Canada.

15. Pipe SW. The hope and reality of long-acting hemophilia products. Am J Hematol. 2012;87(suppl 1):S33-S39.

16. Metzner HJ, Weimer T, Kronthaler U, Lang W, Schulte S. Genetic fusion to albumin improves the pharmacokinetic properties of factor IX. Thromb Haemost. 2009;102(4):634-644.

17. Peters RT, Low SC, Kamphaus GD, et al. Prolonged activity of factor IX as a monomeric Fc fusion protein. Blood. 2010;115(10):2057-2064.

18. Negrier C, Knobe K, Tiede A, Giangrande P, Møss J. Enhanced pharmacokinetic properties of a glycoPEGylated recombinant factor IX: a first human dose trial in patients with hemophilia B. Blood. 2011; 118(10):2695-2701.

19. Sternebring O, Christensen JK, Bjørnsdottir I. Pharmacokinetics, tissue distribution, excretion, and metabolite profiling of PEGylated rFIX (nonacog beta pegol, N9-GP) in rats. Eur J Pharm Sci. 2016;92: 163-172.

20. Rasmussen CE, Nowak J, Larsen JM, Bottomley A, Rowles A, Offenberg $\mathrm{H}$. Evaluation of nonacog beta pegol long-term safety in the immune-deficient Rowett nude rat (Crl:NIH-Foxn1rnu). Toxicol Pathol. 2016;44(5):726-737.
21. Coagulation Factor IX (Recombinant), GlycoPEGylated (N9-GP). FDA Briefing Document. Bagsværd, Denmark: Novo Nordisk, Inc.; 2017; 125611BLA.

22. Collins PW, Young G, Knobe K, et al. Recombinant long-acting glycoPEGylated factor IX in hemophilia B: a multinational randomized phase 3 trial. Blood. 2014;124(26):3880-3886.

23. Escobar MA, Tehranchi R, Karim FA, et al. Low-factor consumption for major surgery in haemophilia B with long-acting recombinant glycoPEGylated factor IX. Haemophilia. 2017;23(1):67-76.

24. Young G, Collins PW, Colberg T, et al. Nonacog beta pegol (N9-GP) in haemophilia B: a multinational phase III safety and efficacy extension trial (paradigm4). Thromb Res. 2016;141:69-76.

25. Carcao M, Zak M, Abdul Karim F, et al. Nonacog beta pegol in previously treated children with hemophilia B: results from an international open-label phase 3 trial. J Thromb Haemost. 2016;14(8):1521-1529.

26. Novo Nordisk AS [webpage on the Internet]. Safety and Efficacy of Nonacog beta Pegol (N9-GP) in Previously Untreated Patients With Haemophilia B (paradigm ${ }^{\mathrm{TM}} 6$ ). 2017. Available from: https://clinicaltrials.gov/ct2/show/NCT02141074. NLM identifier: NCT02141074. Accessed May 23, 2017.

27. Collins PW, Blanchette VS, Fischer K, et al; rAHF-PFM Study Group. Break-through bleeding in relation to predicted factor VIII levels in patients receiving prophylactic treatment for severe hemophilia A. J Thromb Haemost. 2009;7(3):413-420.

28. Tiede A, Abdul-Karim F, Carcao M, et al. Pharmacokinetics of a novel extended half-life glycoPEGylated factor IX, nonacog beta pegol (N9-GP) in previously treated patients with haemophilia B: results from two phase 3 clinical trials. Haemophilia. 2017;23(4): $547-555$.

29. Negrier C, Young G, Abdul Karim F, et al; paradigm ${ }^{\text {TM }} 2$ and 4 Investigators. Recombinant long-acting glycoPEGylated factor IX (nonacog beta pegol) in haemophilia B: assessment of target joints in multinational phase 3 clinical trials. Haemophilia. 2016;22(4):507-513.

30. Carcao M, Khodaie M, Ehrenforth S, et al. Nonacog beta pegol for the prophylactic treatment of children with haemophilia B: interim results from the paradigm ${ }^{\mathrm{TM}} 5$ clinical trial. The 10th Annual Congress of the European Association for Haemophilia and Allied Disorders. Paris, France: February 1-3, 2017.

31. Ragni MV, Pasi KJ, White GC, et al; Recombinant FIX Surgical Study Group. Use of recombinant factor IX in subjects with haemophilia B undergoing surgery. Haemophilia. 2002;8(2):91-97.

32. Roth DA, Kessler CM, Pasi KJ, et al; Recombinant Factor IX Study Group. Human recombinant factor IX: safety and efficacy studies in hemophilia B patients previously treated with plasma-derived factor IX concentrates. Blood. 2001;98(13):3600-3606.

33. Windyga J, Lissitchkov T, Stasyshyn O, et al. Efficacy and safety of a recombinant factor IX (Bax326) in previously treated patients with severe or moderately severe haemophilia B undergoing surgical or other invasive procedures: a prospective, open-label, uncontrolled, multicentre, phase III study. Haemophilia. 2014;20(5):651-658.

34. Neufeld EJ, Solimeno L, Quon D, et al. Perioperative management of haemophilia B: a critical appraisal of the evidence and current practices. Haemophilia. 2017;23(6):821-831.

35. Collins P, Carcao M, Simonsen M, et al. Safety of nonacog beta pegol (N9-GP): results from the paradigm ${ }^{\mathrm{TM}}$ clinical trials. Poster presented at: The 26th Congress of the International Society on Thrombosis and Haemostasis, July 11 2017. Berlin, Germany.

36. Stidl R, Fuchs S, Bossard M, Siekmann J, Turecek PL, Putz M. Safety of PEGylated recombinant human full-length coagulation factor VIII (BAX 855) in the overall context of PEG and PEG conjugates. Haemophilia. 2016;22(1):54-64.

37. European Medicines Agency. CHMP Safety Working Party's Response to the Paediatric Committee Regarding the Use of PEGylated Drug Products in the Paediatric Population; 2012. Available from: http:// www.ema.europa.eu/docs/en_GB/document_library/Scientific_ guideline/2012/11/WC500135123.pdf. Accessed April 5, 2018. 
38. Webster R, Didier E, Harris P, et al. PEGylated proteins: evaluation of their safety in the absence of definitive metabolism studies. Drug Metab Dispos. 2007;35(1):9-16.

39. Chowdary P, Kearney S, Regnault A, Hoxer CS, Yee DL. Improvement in health-related quality of life in patients with haemophilia B treated with nonacog beta pegol, a new extended half-life recombinant FIX product. Haemophilia. 2016;22(4):e267-e274.

40. Iorio A, Puccetti P, Makris M. Clotting factor concentrate switching and inhibitor development in hemophilia A. Blood. 2012;120(4):720-727.

41. Oldenburg J. Optimal treatment strategies for hemophilia: achievements and limitations of current prophylactic regimens. Blood. 2015; 125(13):2038-2044.

42. Fischer K, Ljung R. Primary prophylaxis in haemophilia care: guideline update 2016. Blood Cells Mol Dis. 2017;67:81-85.

43. Zhang R, Wang Q, Zhang L, Chen S. Optimized human factor IX expression cassettes for hepatic-directed gene therapy of hemophilia B. Front Med. 2015;9(1):90-99.
44. Alnylam. Alnylam and Sanofi Genzyme Report Positive Results from Ongoing Phase 2 Open-Label Extension Study with Investigational RNAi Therapeutic Fitusiran in Patients with Hemophilia A and B With or Without Inhibitors. 2017. Available from: http://investors.alnylam. com/news-releases/news-release-details/alnylam-and-sanofi-genzymereport-positive-results-ongoing-phase. Accessed August 17, 2018.

45. Alnylam [webpage on the Internet]. An Open-Label Extension Study of an Investigational Drug, ALN-AT3SC, in Patients With Moderate or Severe Hemophilia A or B. 2017. Available from: https://clinicaltrials.gov/ct2/show/NCT02554773. NLM identifier: NCT02554773. Accessed June 7, 2017.

46. Pasi KJ, Rangarajan S, Georgiev P, et al. Targeting of antithrombin in hemophilia A or B with RNAi therapy. N Engl J Med. 2017;377(9): 819-828.

\section{Publish your work in this journal}

Drug Design, Development and Therapy is an international, peerreviewed open-access journal that spans the spectrum of drug design and development through to clinical applications. Clinical outcomes, patient safety, and programs for the development and effective, safe, and sustained use of medicines are the features of the journal, which has also been accepted for indexing on PubMed Central. The manuscript management system is completely online and includes a very quick and fair peer-review system, which is all easy to use. Visit http://www.dovepress.com/testimonials.php to read real quotes from published authors.

Submit your manuscript here: http://www.dovepress.com/drug-design-development-and-therapy-journal 